\title{
ERRATUM
}

\section{THE ROLE OF VISUAL PREFERENCES IN ARCHITECTURE VIEWS}

https://doi.org/10.3846/jau.2020.12582

The article "The role of visual preferences in architecture views" by Ali Akbar Amini, Bahman Adibzadeh, published on 24 September 2020 in the Journal of Architecture and Urbanism, 44(2), 122-127, contained a following errors on:

$122 \mathrm{p}$. The source is incorrectly cited in the text. The correct citation is:

(de la Fuente Suárez, 2016)

$126 \mathrm{p}$. The references incorrectly indicate author name, lastname and title of article. The correct citation is:

de la Fuente Suárez, L. A. (2016). Towards experiential representation in architecture. Journal of Architecture and Urbanism, 40(1), 47-58. https://doi.org/10.3846/20297955.2016.1163243

Corrected version of the article is available online.

The publisher apologises for this error. 